\title{
ДВЕ ВОЛНЫ В ДИНАМИКЕ ЗАБОЛЕВАЕМОСТИ КОРОНАВИРУСОМ В РЕСПУБЛИКЕ БЕЛАРУСЬ.
}

\author{
П.С. Гринчук, С.П. Фисенко \\ Институт тепло- и массообмена имени А.В. Лыкова НАН Беларуси, г. Минск. \\ gps@hmti.ac.by \\ (20 мая 2020 г.)
}

В данной работе на основании анализа статистических данных по заболеваемости коронавирусом в Республике Беларусь за период с 6 марта по 19 мая 2020 г. выполнен уточненный прогнозный расчет динамики заболеваемости коронавирусом на территории Республики Беларусь. На основании модели двух волн заболевания коронавирусом, распространяющихся независимо в населенных пунктах с различной плотностью населения, получено качественное объяснение и количественное описание длительного плато по количеству заболевших в сутки на уровне $900-950$ новых случаев в день. Пик заболеваемости по уточненным прогнозным данным приходится на период с 28 апреля по 25-29 мая, когда в день может фиксироваться более 800 новых случаев. Максимальное прогнозное количество заболевших, по уточненным данным, может достичь 56 тысяч человек. Середина (медиана) эпидемии по прогнозному расчету пройдена в районе 15 мая, когда общее количество заболевших достигло 50\% (около 28 тысяч заболевших) от общего прогнозного. Уменьшение уровня заболеваемости до 100 новых случаев в день прогнозируется на период 8-14 июля. На краткосрочную перспективу в 30-50 дней точность прогноза по количеству заболевших оценивается в 10-15\%, по конкретным датам - плюс-минус 5-7 дней.

Данную работы нам хотелось бы начать с цитаты свежей новостной ленты о проблеме прогнозирования заболеваемости коронавирусом [1]. Согласно мнению американского математика Мака Хайнмана из Тулейнского университета Луизианы (США), прогнозирование распространения COVID-19 является одним из самых сложных этапов борьбы с пандемией. Специалисты со всего мира работают в этом направлении. По словам математика, с абсолютной точностью предсказать дальнейшее распространение COVID-19 нельзя. Однако прогнозирование можно улучшить, если проводить корректировку используемых математических методов, уточнять исходную информацию и проводить сравнительный анализ прогнозов. Согласно словам Хайнмана, «...сообщество ученых, занимающихся моделированием, было удивлено тем, как сложно оказалось точно предсказать даже рецидивную инфекцию, передаваемую воздушно-капельным путем. Потребовалось несколько лет, прежде чем появились надежные модели, подтвердившиеся в нескольких последних эпидемиях».

Уже минуло 50 дней с момента, когда в Республике Беларусь было зарегистрировано более 100 заболевших коронавирусом (30 марта 2020 г.). Накопившиеся данные по заболеваемости позволяют проверить и уточнить сделанные нами ранее прогнозы [2,3]. Согласно уточненному прогнозу от 1 мая [3], к 19 мая уровень заболеваемости должен был достигнуть $28680 \pm 4300$ случаев ( $\pm 15 \%)$. Фактические данные составляют 31508 случаев [4] (рисунок 1), что укладывается в пределы погрешности. Одной из особенностей, которая активно обсуждается в обществе и СМИ последнее время, стало длительное пребывание статистики по заболеванию на плато с более 900 новых ежедневных случаев. Это несколько противоречит первоначальным прогнозам, согласно которым после 4 мая должен был намечаться постепенный спад. Отметим, что первоначально именно так и произошло - 4 мая число ежедневных новых случаев снизилось до 784, по сравнению с 973 случаями 29 апреля (рисунок 2). Но, после этого, статистика вернулась и застыла на отметке 920-950 новых случаев в день. Попытка разобраться в этом и объяснить такое поведение послужила главным мотивом для этой работы. Отметим, что для анализа ситуации мы обратимся к статистике по заболеваемости в Швеции (рисунок 3), которая сходна с Республикой Беларусь по количеству населения и отсутствию жестких карантинных мер и к индексу самоизоляции населения в различных городах, который составляется порталом Яндекс по своей методике (рисунок 4). 


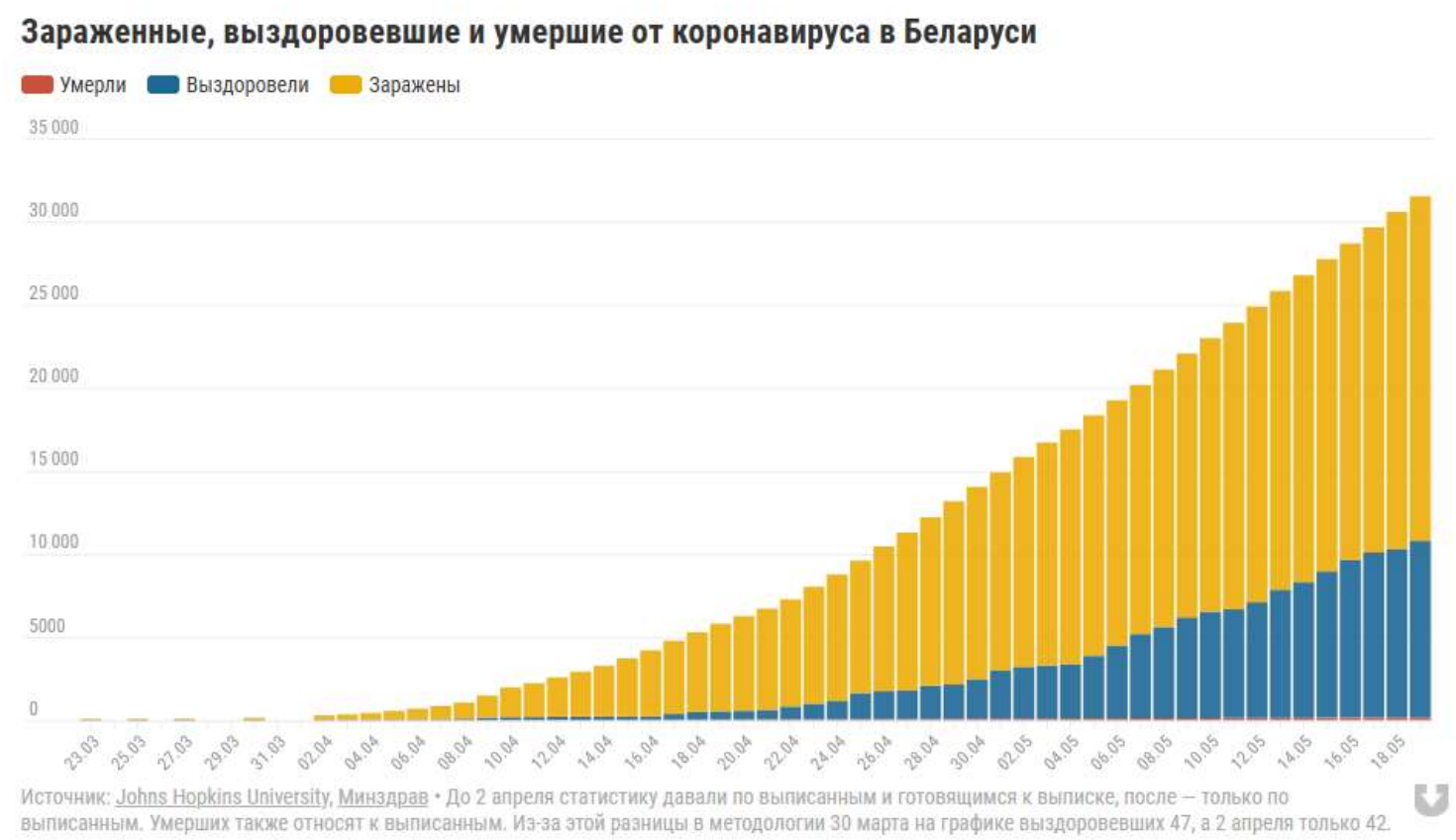

Рисунок 1. Данные по заболеваемости коронавирусом в Республике Беларусь по состоянию на 19 мая 2020 [4].

В качестве базового инструмента математического анализа имеющихся данных по-прежнему будет использоваться подход, описанный в работе [5]. Суть анализа состоит в построении зависимости новых случаев заболевания от случаев в предыдущий день в логарифмических координатах. Выявляемая при этом степенная зависимость позволяет определить относительно точные числовые значения коэффициентов $\alpha$ и $\beta$ для этой зависимости согласно уравнению

$$
C(n+1)=\alpha[C(n)]^{\beta} .
$$

Отметим, что используемый подход находится в русле логистических моделей популяционной динамики и распространения заболеваний [6-8] и берут свое начало в модели бельгийского математика Пьера Ферхлюста, впервые сформулированной еще в середине 19 века [9].

Попытка уточнения коэффициентов $\alpha$ и $\beta$ по новым данным (рисунок 5) выявила интересную закономерность. K дате 1 мая эти показатели стабилизировались (рисунок 6), но после этого последовало их изменение, достаточно заметное с точки зрения долгосрочного поведения системы. Такое поведение не укладывалось в рамки принятой модели, на основе которой строился анализ и прогноз. Если модели поведения внутри популяции не изменялись и не изменялась методика анализа, то коэффициенты должны оставаться постоянными. Каких-либо крупных событий, связанных с изменением коллективного поведения в этот период, также не происходило. Это можно видеть по поведению индекса самоизоляции для различных городов Республики Беларусь (рисунок 4). Отметим, что если бы какое-либо влияние на количество новых случаев оказывало проведение массовых мероприятий, то мы бы, наиболее вероятно, наблюдали кратковременные всплески. Но такие всплески не наблюдаются (рисунок 2). В то же время для похожей по численности населения Швеции четко прослеживаются семидневные циклы с максимумами в середине недели и с минимумами в субботупонедельник, т.е. на выходные дни (рисунок 3). Это может быть примером проявления более высокой интенсивности социальных контактов в определенные дни недели, особенностей коллективного поведения, существующих традиций в конкретной стране. Отметим, что такое же ярко выраженное цикличное поведение заболеваемости с семидневным периодом наблюдается и в ряде других стран: США, Италия, Германия и др. [10]. Все это натолкнуло нас на мысль о поиске других причин для наблюдаемой динамики заболеваемости коронавирусом в Республике Беларусь. 


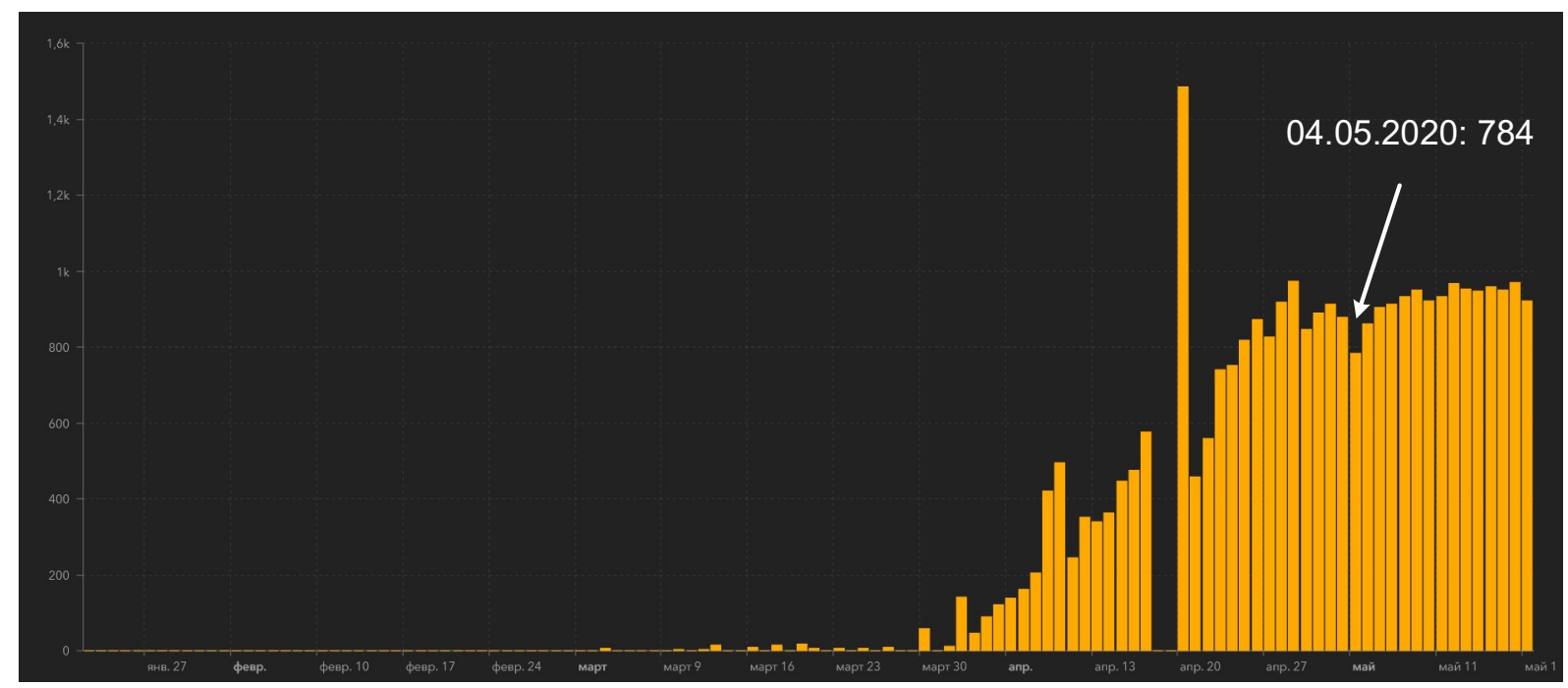

Рисунок 2. Данные по ежедневным новым случаям заболеваемости коронавирусом в Республике Беларусь по состоянию на 19 мая 2020 [10].

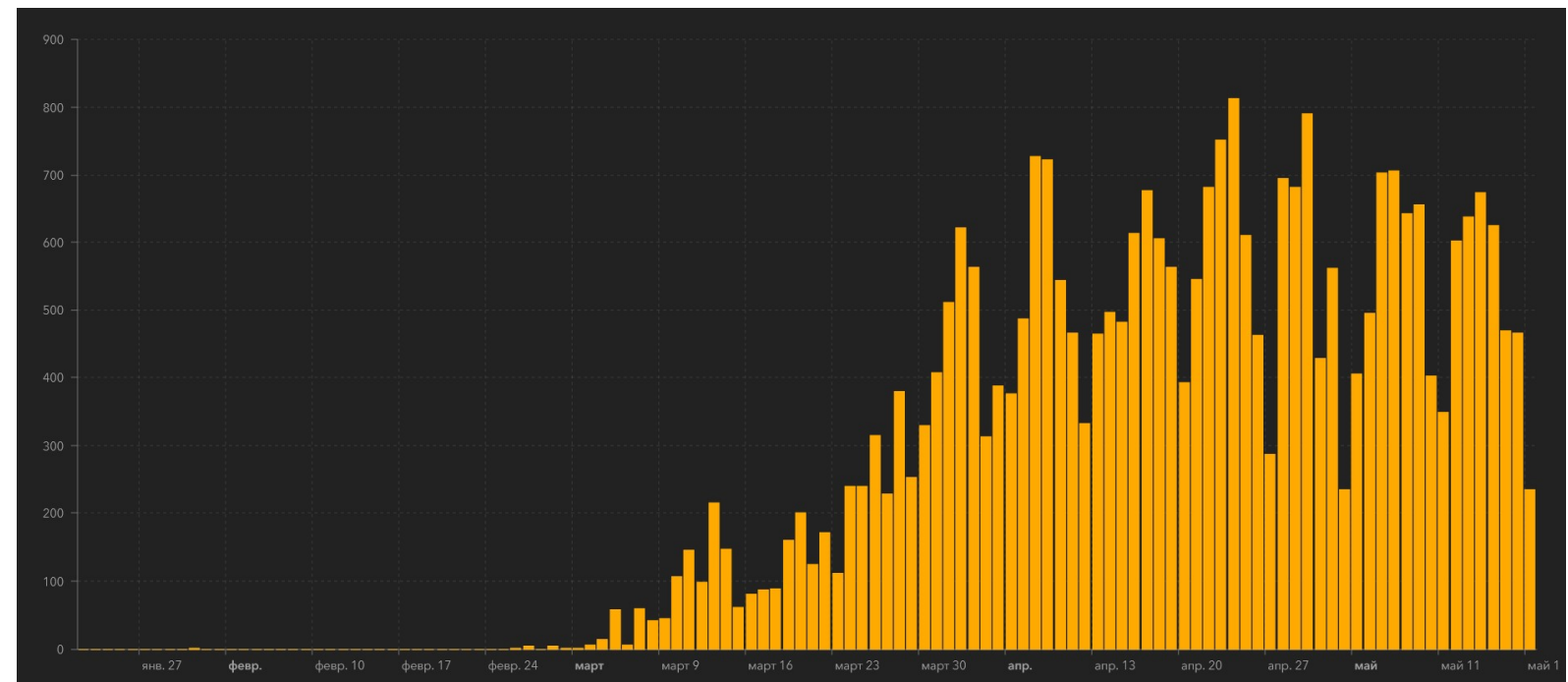

Рисунок 3. Данные по ежедневным новым случаям заболеваемости коронавирусом в Швеции по состоянию на 19 мая 2020 [10]. Видны ярко выраженные семидневные циклы, минимумы которых в большинстве случаев приходятся на выходные дни.

Минск

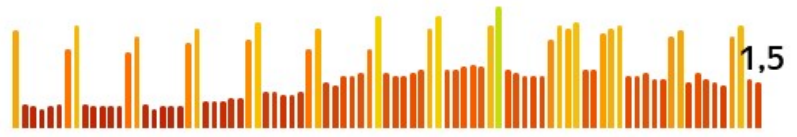

23 февраля
19 мая
Гомель

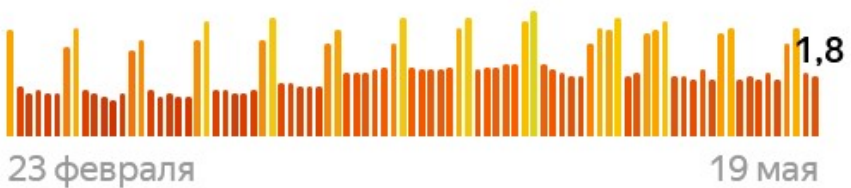

\section{Витебск}

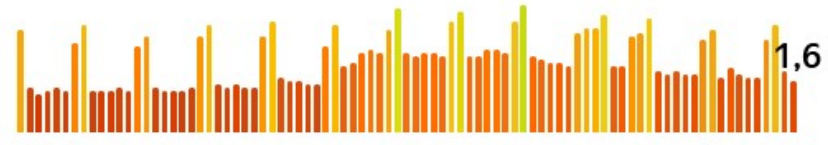

23 февраля
19 мая

\section{Пинск}

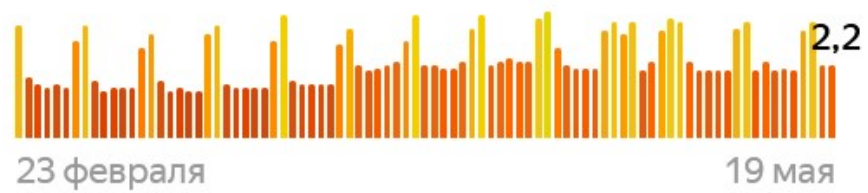

Рисунок 4. Индекс самоизоляции для некоторых белорусских городов согласно данным портала Яндекс [11]. 


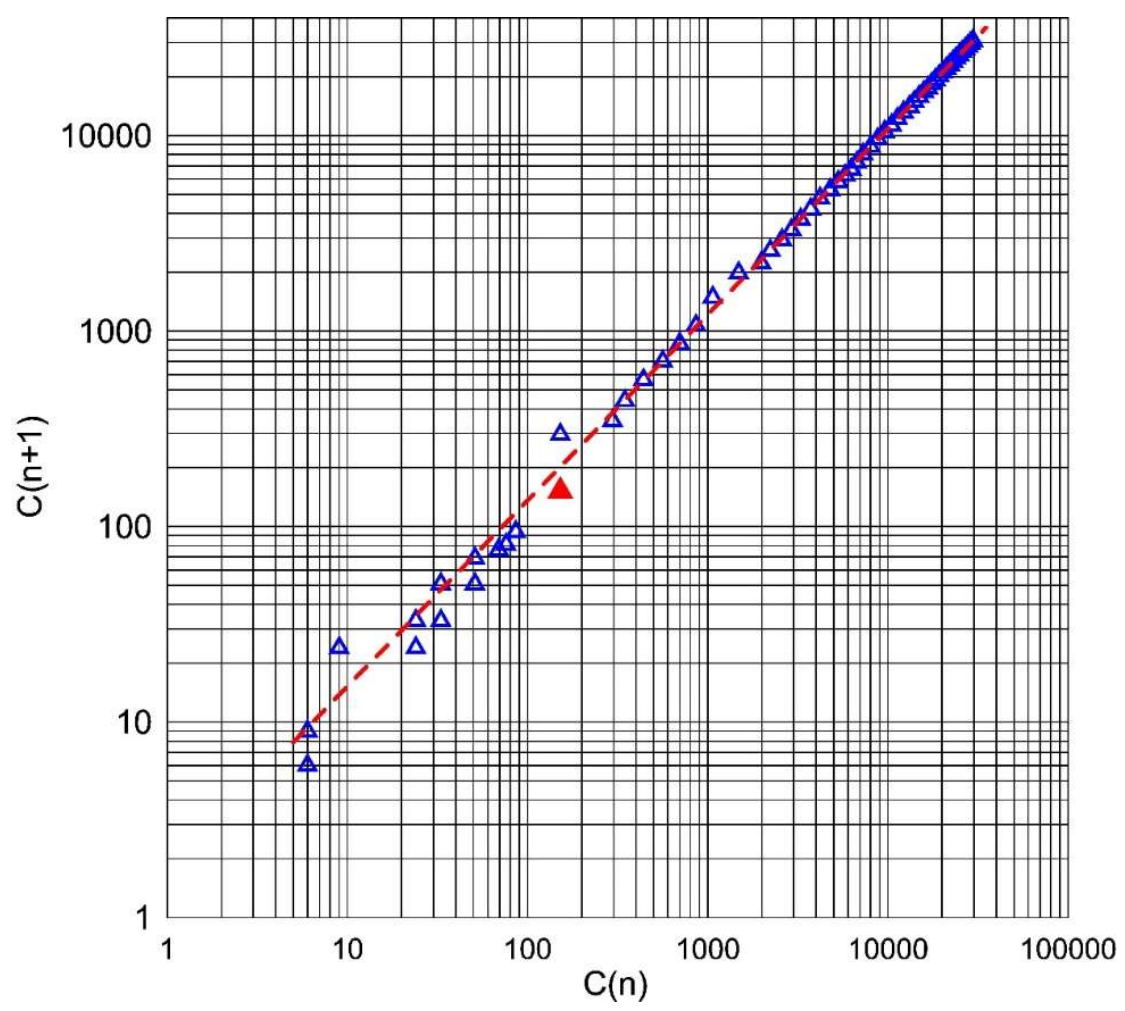

Рисунок 5. Уточненная зависимость количества вовлеченных в заболевание коронавирусом $\mathrm{C}(\mathrm{n}+1)$ в день $\mathrm{n}+1$ от количества вовлеченных в предыдущий день $\mathrm{C}(\mathrm{n})$ по статистическим данным заболеваемости коронавирусом в Республике Беларусь в период с 06 марта по 18 мая апреля 2020 г. [3]. Аппроксимация за период 30 марта (красный символ) - 18 мая.
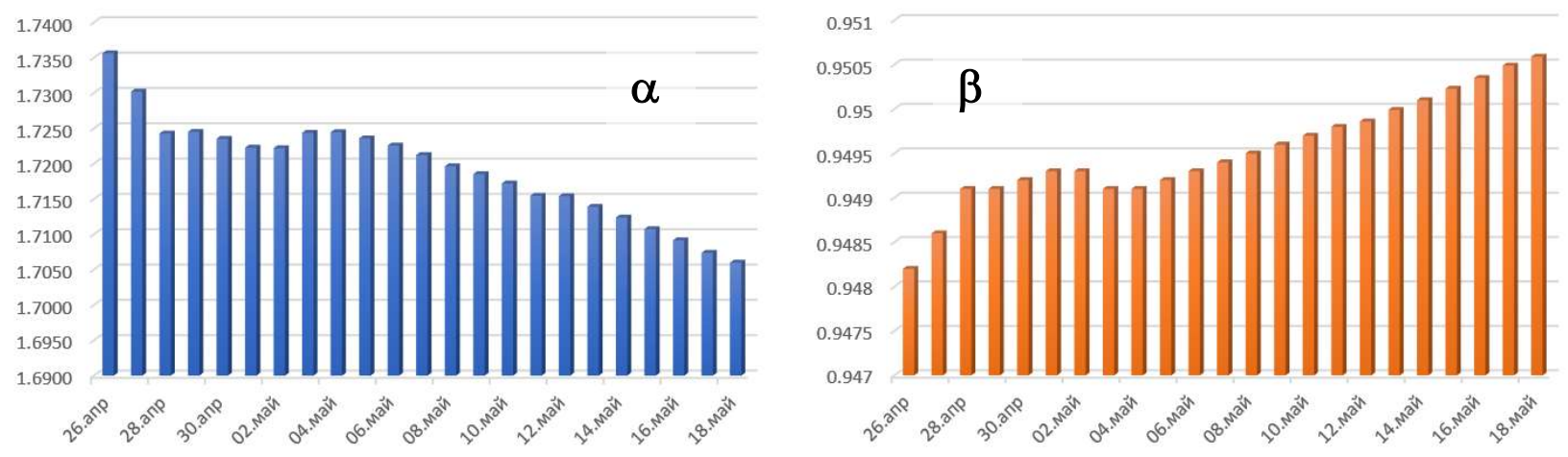

Рисунок 6. Изменение в период 26 апреля - 18 мая коэффициентов $\alpha$ и $\beta$ в уравнении (1), полученные на основании накапливающихся статистических данных [4,10] по заболеваемости коронавирусом в Республике Беларусь по методике, изображенной на рисунке 5.

В результате анализа возможных причин мы пришли к выводу, что причина кроется в региональных особенностях распределения населения по населенным пунктам и возникновении второй волны вируса. Суть этого явления, по нашему мнению, в следующем. В начале эпидемии все страны закрыли свои границы. Поэтому каждую из стран, в том числе и Республику Беларусь, можно рассматривать как замкнутую популяцию. Однако внутри этой популяции население распределено неравномерно. Наверное, неоспоримым является тот факт, что плотность населения является одним из ключевых факторов, влияющих на распространение вируса. В больших городах с высокой плотностью распространение вируса наиболее интенсивно. Печальными примерами этому в ситуации с коронавирусом служат Нью-Йорк и Москва. Таким образом, с точки зрения плотности населения Республику Беларусь можно условно разбить на 3 агломерации: 1) город Минск, плотность населения 5800 чел./км² ; 2) областные центры, где плотность населения от 2400 чел./км² (Брест) - 2600 чел./км² 
(Гродно) до 3800 чел./км² (Гомель), и крупные города областного подчинения (Полоцк, Орша, Бобруйск, Пинск и т.д.), с плотностью населения от 2100 чел./км² (Полоцк) до 2950 чел./км² (Орша); 3) средние и малые райцентры и сельские поселения с плотностью населения в десятки-сотни человек на квадратный километр. Отметим, что средняя плотность населения для Республики Беларусь составляет 46 чел./км². Распространение вируса в каждой из этих агломераций должно происходить со своей скоростью, начало заболеваемости в каждой из агломераций также может быть смещено по времени. Логично предположить, что распространение заболевания начинается в самом большом населенном пункте с самой высокой плотностью населения и затем, с определенной задержкой, заболевание приходит в агломерацию с меньшей плотностью. С определенной степенью достоверности можно считать, что заболевание в каждой из агломераций протекает независимо (распространяется преимущественно внутри субпопуляции). Эти рассуждения лежат в основе проделанного ниже анализа.

Мы предположили, что наблюдаемая ситуация с заболеваемостью может быть описана точнее, если допустить ее распространение в виде двух волн, которые независимо развиваются в двух крупнейших из описанных выше агломераций. При этом мы предположили, что характеристики первой, наиболее интенсивной волны, остались неизменными и могут быть описаны параметрами, полученным по данным на начало мая месяца в работе [3]. Новые данные и их отклонение от прогнозной кривой для одной волны распространения мы использовали для идентификации параметров второй волны. При этом мы предположили, что коэффициенты $\alpha$ и $\beta$ для второй волны не должны радикально отличаться от параметров первой волны. Такой подход позволит непротиворечиво объяснить изменение со временем коэффициентов $\alpha$ и $\beta$, определенных в приближении одной волны (рисунок 6). Статистика по ежедневным случаям позволила предположить, что вторая волна начала оказывать заметное влияние приблизительно в первых числах мая (рисунок 2). Это предположение подтвердилось данными анализа, приведенными ниже.

Таким образом, в рамках сделанного предположения эпидемическая ситуация с коронавирусом в Республики Беларусь должна описываться двумя независимыми волнами

$$
C(n)=C_{1}(n)+C_{2}(n)
$$

Здесь $\mathrm{n}$ - это количество дней с начала распространения эпидемии. Как отмечалось выше, в качестве точки отсчета выбирается день, когда общее количество случаев превысило 100. Для республики Беларусь это 30 марта.

Для первой волны согласно [3] и сделанным выше предположениями справедливы следующие соотношения:

$$
\begin{gathered}
C_{1}(n+1)=\alpha_{1}\left[C_{1}(n)\right]^{\beta_{1}}, \\
C_{1}(n)=\alpha_{1}^{\frac{1-\beta_{1}^{n}}{1-\beta_{1}}}\left[C_{1}(0)\right]^{\beta_{1}^{n}}, \\
\alpha_{1}=1.71(7), \beta_{1}=0.949, C_{1}(0)=100 .
\end{gathered}
$$

Вторая волна описывается следующими соотношениями:

$$
\begin{gathered}
C_{2}\left(n_{2}+1\right)=\alpha_{2}\left[C_{1}\left(n_{2}\right)\right]^{\beta_{2}}, \\
C_{2}\left(n_{2}\right)=\alpha_{2}{ }^{\frac{1-\beta_{2}}{{ }^{n_{2}}}}\left[C_{2}(0)\right]^{\beta_{2}^{n_{2}}}, \\
n_{2}=n-\Delta n .
\end{gathered}
$$

Здесь $\Delta n$ - время задержки второй волны относительно первой (в днях). Таким образом, по имеющимся данным необходимо определить 4 параметра для второй волны: $\alpha_{2}, \beta_{2}, C_{2}(0), \Delta n$. В П.С. Гринчук, С.П. Фисенко. Прогноз заболеваемости коронавирусом. Две волны. 20.05.2020 Страница 5 
качестве целевой функции рассматривалось среднеквадратичное отклонение расчетных и фактических данных по общему количеству случаев заболевания за весь период. Поиск оптимальных параметров осуществлялся градиентным методом наискорейшего спуска [12]. Результаты такого оптимизационного поиска оказались следующими:

$$
\alpha_{2}=1.72(7), \beta_{2}=0.942, C_{2}(0)=24, \Delta n=25 \text {. }
$$

Важно отметить, что вторая волна описывается близкими по величине к параметрам первой волны коэффициентами $\alpha_{2}, \beta_{2}$. Она отличается, как мы и ожидали, меньшим начальным значением числа заболевших $C_{2}(0)$, и характеризуется смещением ориентировочно в 25 дней относительно первой волны (см. уравнения (5) и (9)).

Результаты прогнозного расчета в приближении двух волн по соотношениям (2)-(9) представлены на рисунках 7,8 и в таблице приложения. Для наглядности, на рисунке 8 выделен вклад каждой из двух волн. Как можно видеть, представленное приближение заметно точнее предыдущего описывает развитие ситуации с заболеваемостью коронавирусом в Республике Беларусь по состоянию на май месяц 2020 г. Никаких аномалий статистики в нашей стране нет. Все можно описать и объяснить достаточно простыми методами и понятиями.

Кратко остановимся на анализе данных уточненной модели. Новая модель не противоречит предыдущему анализу [2], а только уточняет его наличием и описанием второй волны меньшей интенсивности. Пик заболеваемости по уточненным данным приходится на период с 28 апреля по 2529 мая, когда в день прогнозируется более 800 новых случаев. Максимальное прогнозное количество заболевших, по уточненным данным, может достичь 56 тысяч человек. Середина (медиана) эпидемии по прогнозному расчету пройдена в районе 15 мая, когда общее количество заболевших достигло 50\% (около 28 тысяч заболевших) от общего прогнозного. Достижение уровня заболеваемости в 100 новых случаев в день прогнозируется к 8 -14 июля.

По поводу двух волн, обсуждавшихся выше, можно отметить следующее. Согласно нашей модели, первая волна отвечает за общее количество заболеваний в 44 тысячи, как это и указывалось раньше [3]. Пик заболеваемости в этой волне достигается предположительно в период 28 апреля - 9 мая с количеством случаев более 800 в день. Вторая волна имеет приблизительно в 3-4 раза меньшую интенсивность. Ее начало приходится на 20-25 апреля 2020 г. Эта волна будет отвечать, опять же, предположительно, за 12-13 тысяч случаев заболевания коронавирусом. Пик второй волны достаточно сглажен и растянут во времени. Он, предположительно, приходится на период 12 мая - 9 июня, когда со второй волной связано более 200 новых случаев в день. Длительное плато по заболеваемости объясняется наложением рассматриваемых двух волн (рисунок 8). Более детальная информация представлена в таблице.

Все замечания, сделанные ранее относительно точности прогнозных расчетов [3], остаются справедливыми и в данном случае. Относительную точность прогноза по количеству заболевших можно оценить в 10-15 \%, по датам наступления определенных событий в 5-7 дней, по крайней мере, в первые 30-50 дней от даты составления прогноза. На более долгосрочную перспективу прогнозный расчет может указывать правильные тенденции, но к конкретным цифрам и датам в этом случае опять же нужно относиться с определенной осторожностью $и$ аккуратностью. Еще раз отметим также, что сделанный прогноз по причине специфики его методики справедлив до тех пор, пока условия развития процесса заболеваемости соответствуют условиям, при которых получены исходные статистические данные для прогноза.

Отметим в заключении, что данная работа выполнена в порядке частной инициативы авторов. 


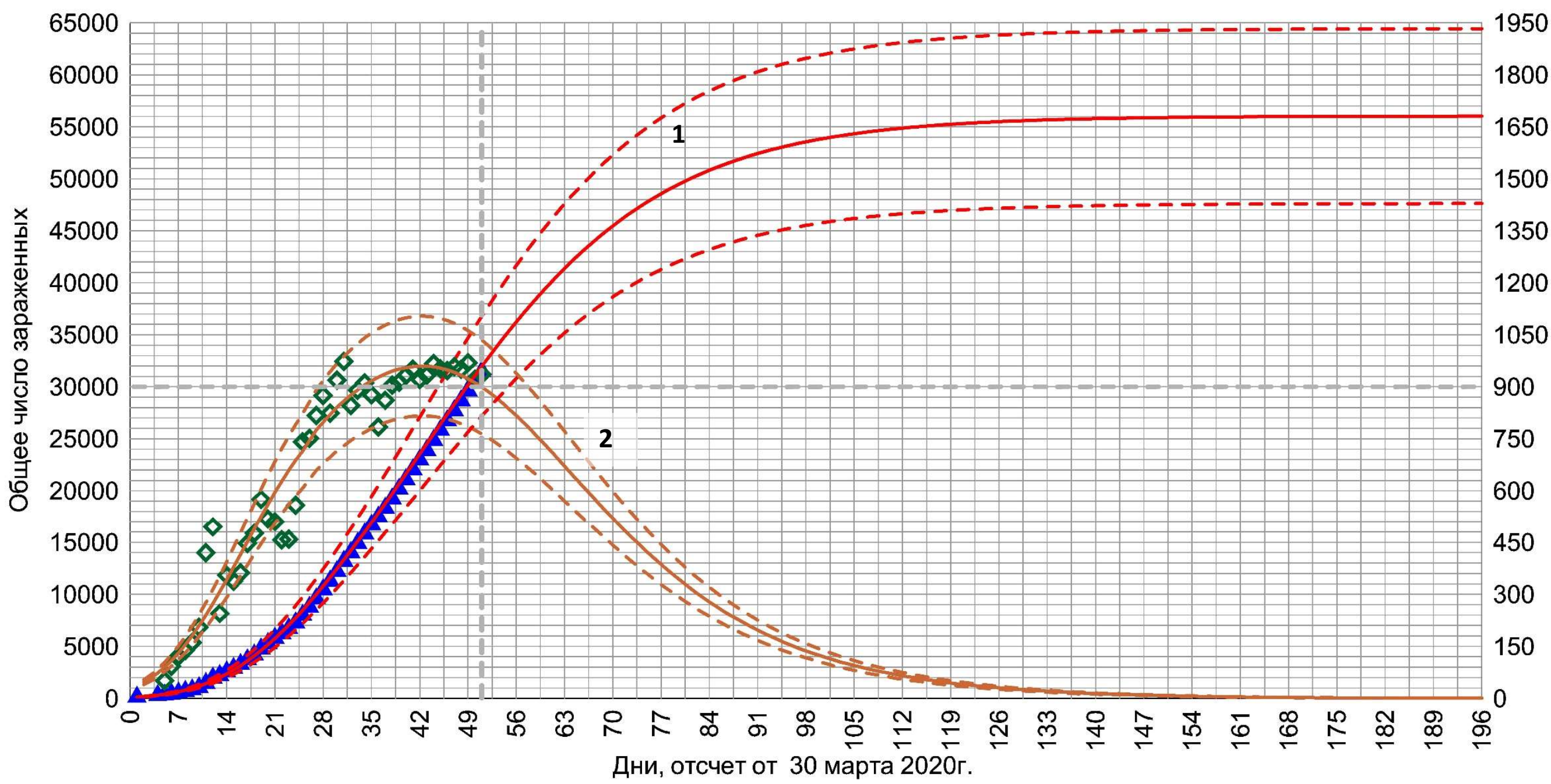

Рисунок 7. Результаты уточненного прогнозного расчета для общего количества заболевших коронавирусом в Республике Беларусь весной-летом 2020 г по данным на 19 мая 2020 г. Кривая 1 (левая ось ординат) - прогнозный расчет для общего количества заболевших; синие символы - фактические данные; 2(правая ось ординат) - прогнозный расчет для количества вновь заболевших в данный день, зеленые символы - фактические данные. Пунктирные линии - область погрешности прогнозных расчетов. 


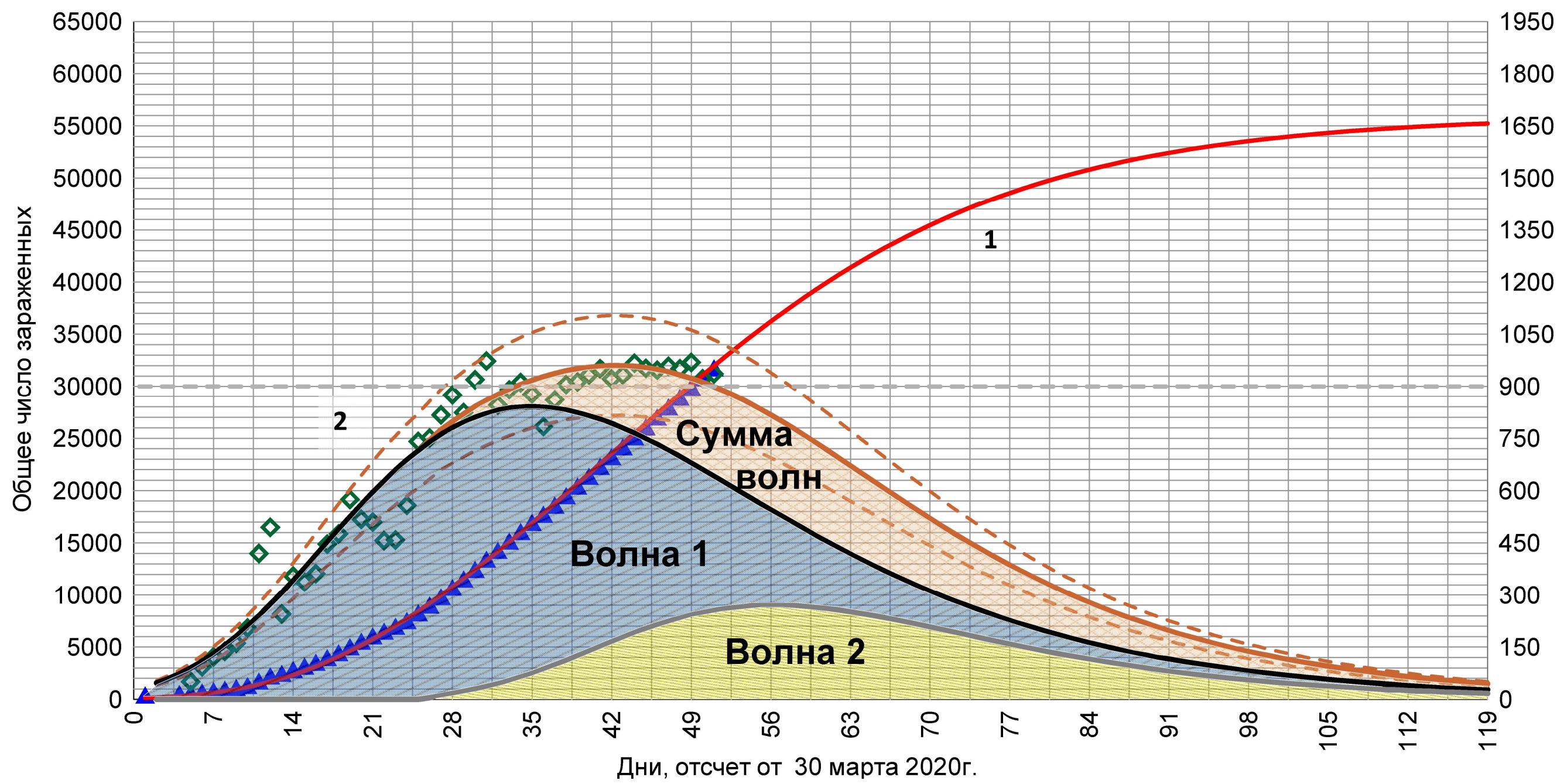

Рисунок 8. Результаты уточненного прогнозного расчета в приближении двух волны для общего количества заболевших коронавирусом в Республике Беларусь весной-летом 2020 г по данным на 30 апреля 2020 г. Кривая 1 (левая ось ординат) - прогнозный расчет для общего количества заболевших; синие символы фактические данные; 2(правая ось ординат) - прогнозный расчет для количества вновь заболевших в данный день, зеленые символы - фактические данные. Цветом показан вклад двух обсуждаемых в тексте работы волн в общую динамику распространения заболевания. 
1. Ученые рассказали, как улучшить прогнозы по COVID-19. РИА Новости, Алексей Богдановский. 20 мая 2020 г. https://ria.ru/20200520/1571705135.html.

2. П.С. Гринчук. Прогноз развития заболеваемости коронавирусом в Республике Беларусь. Preprints.ru. Препринт от 26.04.2020 г. DOI: http://dx.doi.org/10.24108/preprints-3112033

3. П.С. Гринчук. Прогноз развития заболеваемости коронавирусом в Республике Беларусь. Уточненные данные. Preprints.ru. Препринт от 01.05 .2020 г. DOI: https://doi.org/10.24108/preprints-3112037

4. Последняя информация о коронавирусе в Беларуси и мире (URL https://news.tut.by/coronavirusmap/).

5. Fanelli D., Piazza F. Analysis and forecast of COVID-19 spreading in China, Italy and France // Chaos, Solitons \& Fractals. 2020. V. 134. Art. \# 109761.

6. Blumberg A. A. Logistic growth rate functions //Journal of Theoretical Biology. 1968. V. 21. Iss. 1. Pp. 42-44.

7. A. Tsoularis, J. Wallace. Analysis of logistic growth models // Mathematical Biosciences. 2002. V. 179. Iss. 1. Pp. 21-55.

8. А.А. Куркин, О.Е. Куркина, Е.Н. Пелиновский. Логистические модели распространения эпидемий. Труды НГТУ им. Р.Е. Алексеева. 2020. № 2 (129). С. 9-18.

9. P.F. Verhulst. Notice sur la loi que la population poursuit dans son accroissement // Correspondance Mathematique et Physique, 1838, V. 10. P. 113-121.

10. COVID-19 Dashboard by the Center for Systems Science and Engineering at Johns Hopkins University. https://www.arcgis.com/apps/opsdashboard/index.html\#/bda7594740fd40299423467b48e9ecf6

11. Пространственно-временная карта индекса самоизоляции населения разных стран. https://vandex.by/maps/covid19/isolation?ll=30.723194\%2C51.031939\&z=5.4

12. Г. Корн, Т. Корн. Справочник по математике: Пер. с англ. Под ред. И.Г. Арамановича. М.: Наука. 1978. 
Приложение. Результаты прогнозного расчета заболеваемости коронавирусом в Республике Беларусь в период весны-лета 2020 г. по уточненным данным от 19 мая 2020 г [4]. Расчет выполнен в приближении двух волн распространения заболевания (уравнения (2)-(9)). Точность прогнозного расчета оценивается в 10-15\% на период 30-50 дней.

\begin{tabular}{|c|c|c|c|c|c|c|c|c|c|}
\hline Дата & $\begin{array}{l}\text { День } \\
\text { отсчета }\end{array}$ & 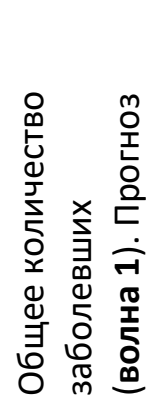 & 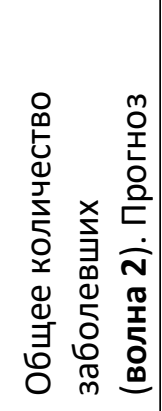 & 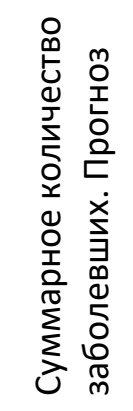 & 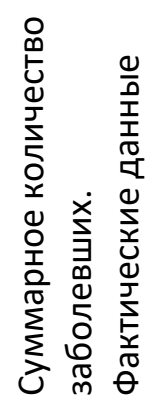 & 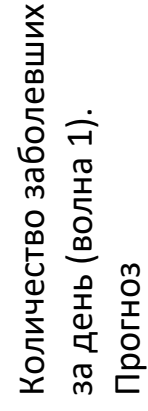 & 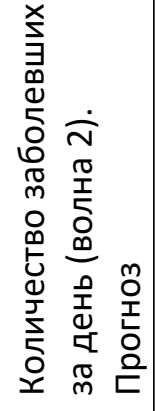 & 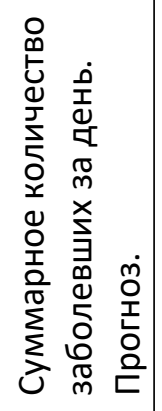 & 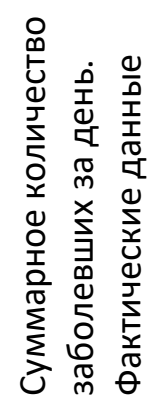 \\
\hline 1 & 2 & 3 & 4 & 5 & 6 & 7 & 8 & 9 & 10 \\
\hline 30.мар & 1 & 136 & 0 & 136 & 152 & - & - & - & - \\
\hline 31.мар & 2 & 183 & 0 & 183 & & 47 & 0 & 47 & - \\
\hline 01.апр & 3 & 242 & 0 & 242 & & 59 & 0 & 59 & - \\
\hline 02.апр & 4 & 315 & 0 & 315 & 296 & 73 & 0 & 73 & - \\
\hline 03.апр & 5 & 406 & 0 & 406 & 347 & 90 & 0 & 90 & 51 \\
\hline 04.апр & 6 & 515 & 0 & 515 & 440 & 109 & 0 & 109 & 93 \\
\hline 05.апр & 7 & 646 & 0 & 646 & 562 & 131 & 0 & 131 & 122 \\
\hline 06.апр & 8 & 801 & 0 & 801 & 700 & 155 & 0 & 155 & 138 \\
\hline 07.апр & 9 & 982 & 0 & 982 & 861 & 181 & 0 & 181 & 161 \\
\hline 08.апр & 10 & 1192 & 0 & 1192 & 1066 & 210 & 0 & 210 & 205 \\
\hline 09.апр & 11 & 1432 & 0 & 1432 & 1486 & 240 & 0 & 240 & 420 \\
\hline 10.апр & 12 & 1704 & 0 & 1704 & 1981 & 273 & 0 & 273 & 495 \\
\hline 11.апр & 13 & 2011 & 0 & 2011 & 2226 & 307 & 0 & 307 & 245 \\
\hline 12.апр & 14 & 2353 & 0 & 2353 & 2581 & 342 & 0 & 342 & 355 \\
\hline 13.апр & 15 & 2731 & 0 & 2731 & 2919 & 378 & 0 & 378 & 338 \\
\hline 14.апр & 16 & 3146 & 0 & 3146 & 3281 & 415 & 0 & 415 & 362 \\
\hline 15.апр & 17 & 3598 & 0 & 3598 & 3728 & 452 & 0 & 452 & 447 \\
\hline 16.апр & 18 & 4086 & 0 & 4086 & 4204 & 489 & 0 & 489 & 476 \\
\hline 17.апр & 19 & 4611 & 0 & 4611 & 4779 & 525 & 0 & 525 & 575 \\
\hline 18.апр & 20 & 5172 & 0 & 5172 & 5297 & 560 & 0 & 560 & 518 \\
\hline 19.апр & 21 & 5767 & 0 & 5767 & 5807 & 595 & 0 & 595 & 510 \\
\hline 20.апр & 22 & 6394 & 0 & 6394 & 6264 & 627 & 0 & 627 & 457 \\
\hline 21.апр & 23 & 7053 & 0 & 7053 & 6723 & 659 & 0 & 659 & 459 \\
\hline 22.апр & 24 & 7740 & 0 & 7740 & 7281 & 688 & 0 & 688 & 558 \\
\hline 23.апр & 25 & 8454 & 0 & 8454 & 8022 & 714 & 0 & 714 & 741 \\
\hline 24.апр & 26 & 9193 & 34 & 9228 & 8773 & 739 & 34 & 773 & 751 \\
\hline 25.апр & 27 & 9954 & 48 & 10002 & 9590 & 761 & 14 & 775 & 817 \\
\hline 26.апр & 28 & 10734 & 67 & 10801 & 10465 & 780 & 18 & 798 & 875 \\
\hline 27.апр & 29 & 11531 & 90 & 11621 & 11289 & 797 & 24 & 820 & 824 \\
\hline 28.апр & 30 & 12342 & 120 & 12462 & 12208 & 811 & 30 & 841 & 919 \\
\hline 29.апр & 31 & 13164 & 157 & 13321 & 13181 & 822 & 37 & 859 & 973 \\
\hline 30.апр & 32 & 13994 & 203 & 14197 & 14027 & 831 & 45 & 876 & 846 \\
\hline
\end{tabular}

П.С. Гринчук, С.П. Фисенко. Прогноз заболеваемости коронавирусом. Две волны. 20.05.2020 Страница 10 


\begin{tabular}{|c|c|c|c|c|c|c|c|c|c|}
\hline 1 & 2 & 3 & 4 & 5 & 6 & 7 & 8 & 9 & 10 \\
\hline 01.май & 33 & 14831 & 257 & 15088 & 14917 & 837 & 55 & 891 & 890 \\
\hline 02.май & 34 & 15671 & 322 & 15993 & 15828 & 840 & 65 & 905 & 911 \\
\hline 03.май & 35 & 16513 & 398 & 16911 & 16705 & 841 & 76 & 917 & 877 \\
\hline 04.май & 36 & 17353 & 485 & 17839 & 17489 & 840 & 88 & 928 & 784 \\
\hline 05.май & 37 & 18190 & 586 & 18776 & 18350 & 837 & 100 & 937 & 861 \\
\hline 06.май & 38 & 19022 & 699 & 19721 & 19255 & 832 & 113 & 945 & 905 \\
\hline 07.май & 39 & 19846 & 826 & 20672 & 20168 & 824 & 127 & 951 & 913 \\
\hline 08.май & 40 & 20661 & 966 & 21627 & 21101 & 815 & 140 & 955 & 933 \\
\hline 09.май & 41 & 21466 & 1120 & 22586 & 22052 & 805 & 154 & 958 & 951 \\
\hline 10.май & 42 & 22259 & 1287 & 23545 & 22973 & 793 & 167 & 960 & 921 \\
\hline 11.май & 43 & 23038 & 1467 & 24505 & 23906 & 779 & 180 & 959 & 933 \\
\hline 12.май & 44 & 23802 & 1660 & 25462 & 24873 & 765 & 193 & 958 & 967 \\
\hline 13.май & 45 & 24551 & 1865 & 26416 & 25825 & 749 & 205 & 954 & 952 \\
\hline 14.май & 46 & 25284 & 2081 & 27365 & 26772 & 733 & 216 & 949 & 947 \\
\hline 15.май & 47 & 26000 & 2307 & 28307 & 27730 & 716 & 226 & 942 & 958 \\
\hline 16.май & 48 & 26698 & 2543 & 29240 & 28681 & 698 & 236 & 933 & 951 \\
\hline 17.май & 49 & 27377 & 2787 & 30164 & 29650 & 679 & 244 & 923 & 969 \\
\hline 18.май & 50 & 28038 & 3038 & 31076 & 30572 & 661 & 251 & 912 & 922 \\
\hline 19.май & 51 & 28680 & 3295 & 31975 & 31508 & 642 & 257 & 899 & 936 \\
\hline 20.май & 52 & 29302 & 3557 & 32860 & - & 623 & 262 & 885 & - \\
\hline 21.май & 53 & 29906 & 3823 & 33729 & - & 603 & 266 & 870 & - \\
\hline 22.май & 54 & 30490 & 4092 & 34582 & - & 584 & 269 & 853 & - \\
\hline 23.май & 55 & 31055 & 4363 & 35418 & - & 565 & 271 & 835 & - \\
\hline 24.май & 56 & 31601 & 4634 & 36235 & - & 546 & 271 & 817 & - \\
\hline 25.май & 57 & 32128 & 4905 & 37032 & - & 527 & 271 & 798 & - \\
\hline 26.май & 58 & 32636 & 5174 & 37810 & - & 508 & 270 & 778 & - \\
\hline 27.май & 59 & 33125 & 5442 & 38567 & - & 490 & 267 & 757 & - \\
\hline 28.май & 60 & 33597 & 5706 & 39303 & - & 471 & 265 & 736 & - \\
\hline 29.май & 61 & 34050 & 5967 & 40018 & - & 454 & 261 & 715 & - \\
\hline 30.май & 62 & 34486 & 6224 & 40710 & - & 436 & 257 & 693 & - \\
\hline 31.май & 63 & 34905 & 6476 & 41381 & - & 419 & 252 & 671 & - \\
\hline 01.июн & 64 & 35308 & 6723 & 42031 & - & 402 & 247 & 649 & - \\
\hline 02.июн & 65 & 35694 & 6964 & 42658 & - & 386 & 241 & 627 & - \\
\hline 03.июн & 66 & 36064 & 7199 & 43263 & - & 370 & 235 & 605 & - \\
\hline 04.июн & 67 & 36419 & 7427 & 43846 & - & 355 & 229 & 584 & - \\
\hline 05.июн & 68 & 36760 & 7649 & 44408 & - & 340 & 222 & 562 & - \\
\hline 06.июн & 69 & 37085 & 7864 & 44949 & - & 326 & 215 & 541 & - \\
\hline 07.июн & 70 & 37397 & 8072 & 45469 & - & 312 & 208 & 520 & - \\
\hline 08.июн & 71 & 37695 & 8273 & 45969 & - & 298 & 201 & 499 & - \\
\hline 09.июн & 72 & 37981 & 8467 & 46448 & - & 285 & 194 & 479 & - \\
\hline 10.июн & 73 & 38253 & 8654 & 46908 & - & 273 & 187 & 460 & - \\
\hline 11.июн & 74 & 38514 & 8834 & 47348 & - & 261 & 180 & 441 & - \\
\hline 12.июн & 75 & 38763 & 9007 & 47770 & - & 249 & 173 & 422 & - \\
\hline 13.июн & 76 & 39001 & 9173 & 48174 & - & 238 & 166 & 404 & - \\
\hline 14.июн & 77 & 39228 & 9332 & 48560 & - & 227 & 159 & 386 & - \\
\hline
\end{tabular}

П.С. Гринчук, С.П. Фисенко. Прогноз заболеваемости коронавирусом. Две волны. 20.05.2020 Страница 11 


\begin{tabular}{|c|c|c|c|c|c|c|c|c|c|}
\hline 1 & 2 & 3 & 4 & 5 & 6 & 7 & 8 & 9 & 10 \\
\hline 15.июн & 78 & 39444 & 9484 & 48929 & - & 217 & 152 & 369 & - \\
\hline 16.июн & 79 & 39651 & 9630 & 49281 & - & 207 & 146 & 353 & - \\
\hline 17.июн & 80 & 39848 & 9769 & 49618 & - & 197 & 139 & 337 & - \\
\hline 18.июн & 81 & 40036 & 9903 & 49939 & - & 188 & 133 & 321 & - \\
\hline 19.июн & 82 & 40216 & 10030 & 50245 & - & 179 & 127 & 306 & - \\
\hline 20.июн & 83 & 40386 & 10151 & 50537 & - & 171 & 121 & 292 & - \\
\hline 21.июн & 84 & 40549 & 10266 & 50816 & - & 163 & 116 & 278 & - \\
\hline 22.июн & 85 & 40704 & 10377 & 51081 & - & 155 & 110 & 265 & - \\
\hline 23.июн & 86 & 40852 & 10481 & 51333 & - & 148 & 105 & 252 & - \\
\hline 24.июн & 87 & 40993 & 10581 & 51574 & - & 141 & 100 & 240 & - \\
\hline 25.июн & 88 & 41127 & 10676 & 51802 & - & 134 & 95 & 229 & - \\
\hline 26.июн & 89 & 41254 & 10766 & 52020 & - & 128 & 90 & 218 & - \\
\hline 27.июн & 90 & 41376 & 10851 & 52227 & - & 121 & 85 & 207 & - \\
\hline 28.июн & 91 & 41491 & 10932 & 52424 & - & 116 & 81 & 197 & - \\
\hline 29.июн & 92 & 41601 & 11009 & 52610 & - & 110 & 77 & 187 & - \\
\hline 30.июн & 93 & 41706 & 11082 & 52788 & - & 105 & 73 & 178 & - \\
\hline 01.июл & 94 & 41805 & 11151 & 52957 & - & 100 & 69 & 169 & - \\
\hline 02.июл & 95 & 41900 & 11217 & 53117 & - & 95 & 66 & 160 & - \\
\hline 03.июл & 96 & 41990 & 11279 & 53269 & - & 90 & 62 & 152 & - \\
\hline 04.июл & 97 & 42076 & 11338 & 53414 & - & 86 & 59 & 144 & - \\
\hline 05.июл & 98 & 42157 & 11394 & 53551 & - & 81 & 56 & 137 & - \\
\hline 06.июл & 99 & 42235 & 11446 & 53681 & - & 77 & 53 & 130 & - \\
\hline 07.июл & 100 & 42308 & 11496 & 53805 & - & 74 & 50 & 124 & - \\
\hline 08.июл & 101 & 42378 & 11544 & 53922 & - & 70 & 47 & 117 & - \\
\hline 09.июл & 102 & 42445 & 11588 & 54033 & - & 67 & 45 & 111 & - \\
\hline 10.июл & 103 & 42508 & 11630 & 54138 & - & 63 & 42 & 105 & - \\
\hline 11.июл & 104 & 42568 & 11670 & 54238 & - & 60 & 40 & 100 & - \\
\hline 12.июл & 105 & 42625 & 11708 & 54333 & - & 57 & 38 & 95 & - \\
\hline 13.июл & 106 & 42679 & 11744 & 54423 & - & 54 & 36 & 90 & - \\
\hline 14.июл & 107 & 42731 & 11777 & 54508 & - & 52 & 34 & 85 & - \\
\hline 15.июл & 108 & 42780 & 11809 & 54589 & - & 49 & 32 & 81 & - \\
\hline 16.июл & 109 & 42826 & 11839 & 54666 & - & 47 & 30 & 77 & - \\
\hline 17.июл & 110 & 42871 & 11868 & 54738 & - & 44 & 28 & 73 & - \\
\hline 18.июл & 111 & 42913 & 11894 & 54807 & - & 42 & 27 & 69 & - \\
\hline 19.июл & 112 & 42952 & 11920 & 54872 & - & 40 & 25 & 65 & - \\
\hline 20.июл & 113 & 42990 & 11944 & 54934 & - & 38 & 24 & 62 & - \\
\hline 21.июл & 114 & 43026 & 11966 & 54992 & - & 36 & 23 & 59 & - \\
\hline 22.июл & 115 & 43060 & 11987 & 55048 & - & 34 & 21 & 55 & - \\
\hline 23.июл & 116 & 43093 & 12007 & 55100 & - & 32 & 20 & 53 & - \\
\hline 24.июл & 117 & 43124 & 12026 & 55150 & - & 31 & 19 & 50 & - \\
\hline 25.июл & 118 & 43153 & 12044 & 55197 & - & 29 & 18 & 47 & - \\
\hline 26.июл & 119 & 43181 & 12061 & 55242 & - & 28 & 17 & 45 & - \\
\hline 27.июл & 120 & 43207 & 12077 & 55284 & - & 26 & 16 & 42 & - \\
\hline 28.июл & 121 & 43232 & 12092 & 55324 & - & 25 & 15 & 40 & - \\
\hline 29.июл & 122 & 43256 & 12106 & 55362 & - & 24 & 14 & 38 & - \\
\hline
\end{tabular}

П.С. Гринчук, С.П. Фисенко. Прогноз заболеваемости коронавирусом. Две волны. 20.05.2020 Страница 12 


\begin{tabular}{|c|c|c|c|c|c|c|c|c|c|}
\hline 1 & 2 & 3 & 4 & 5 & 6 & 7 & 8 & 9 & 10 \\
\hline 30.июл & 123 & 43279 & 12119 & 55398 & - & 23 & 13 & 36 & - \\
\hline 31.июл & 124 & 43300 & 12132 & 55432 & - & 21 & 13 & 34 & - \\
\hline 01.авг & 125 & 43321 & 12144 & 55464 & - & 20 & 12 & 32 & - \\
\hline 02.авг & 126 & 43340 & 12155 & 55495 & - & 19 & 11 & 31 & - \\
\hline 03.авг & 127 & 43358 & 12166 & 55524 & - & 18 & 11 & 29 & - \\
\hline 04.авг & 128 & 43376 & 12176 & 55551 & - & 17 & 10 & 27 & - \\
\hline 05.авг & 129 & 43392 & 12185 & 55577 & - & 17 & 9 & 26 & - \\
\hline 06.авг & 130 & 43408 & 12194 & 55602 & - & 16 & 9 & 25 & - \\
\hline 07.авг & 131 & 43423 & 12202 & 55625 & - & 15 & 8 & 23 & - \\
\hline 08.авг & 132 & 43437 & 12210 & 55647 & - & 14 & 8 & 22 & - \\
\hline 09.авг & 133 & 43450 & 12217 & 55668 & - & 13 & 7 & 21 & - \\
\hline 10.авг & 134 & 43463 & 12224 & 55687 & - & 13 & 7 & 20 & - \\
\hline 11.авг & 135 & 43475 & 12231 & 55706 & - & 12 & 7 & 19 & - \\
\hline 12.авг & 136 & 43487 & 12237 & 55724 & - & 12 & 6 & 18 & - \\
\hline 13.авг & 137 & 43498 & 12243 & 55741 & - & 11 & 6 & 17 & - \\
\hline 14.авг & 138 & 43508 & 12248 & 55756 & - & 10 & 6 & 16 & - \\
\hline 15.авг & 139 & 43518 & 12254 & 55772 & - & 10 & 5 & 15 & - \\
\hline 16.авг & 140 & 43527 & 12258 & 55786 & - & 9 & 5 & 14 & - \\
\hline 17.авг & 141 & 43536 & 12263 & 55799 & - & 9 & 5 & 13 & - \\
\hline 18.авг & 142 & 43545 & 12267 & 55812 & - & 8 & 4 & 13 & - \\
\hline 19.авг & 143 & 43553 & 12271 & 55824 & - & 8 & 4 & 12 & - \\
\hline 20.авг & 144 & 43560 & 12275 & 55835 & - & 8 & 4 & 11 & - \\
\hline 21.авг & 145 & 43567 & 12279 & 55846 & - & 7 & 4 & 11 & - \\
\hline 22.авг & 146 & 43574 & 12282 & 55857 & - & 7 & 3 & 10 & - \\
\hline 23.авг & 147 & 43581 & 12286 & 55866 & - & 6 & 3 & 10 & - \\
\hline 24.авг & 148 & 43587 & 12289 & 55875 & - & 6 & 3 & 9 & - \\
\hline 25.авг & 149 & 43593 & 12292 & 55884 & - & 6 & 3 & 9 & - \\
\hline 26.авг & 150 & 43598 & 12294 & 55892 & - & 6 & 3 & 8 & - \\
\hline 27.авг & 151 & 43603 & 12297 & 55900 & - & 5 & 3 & 8 & - \\
\hline 28.авг & 152 & 43608 & 12299 & 55908 & - & 5 & 2 & 7 & - \\
\hline 29.авг & 153 & 43613 & 12301 & 55915 & - & 5 & 2 & 7 & - \\
\hline 30.авг & 154 & 43618 & 12304 & 55921 & - & 4 & 2 & 7 & - \\
\hline 31.авг & 155 & 43622 & 12306 & 55927 & - & 4 & 2 & 6 & - \\
\hline 01.сен & 156 & 43626 & 12307 & 55933 & - & 4 & 2 & 6 & - \\
\hline 02.сен & 157 & 43630 & 12309 & 55939 & - & 4 & 2 & 6 & - \\
\hline 03.сен & 158 & 43633 & 12311 & 55944 & - & 4 & 2 & 5 & - \\
\hline 04.сен & 159 & 43637 & 12312 & 55949 & - & 3 & 2 & 5 & - \\
\hline 05.сен & 160 & 43640 & 12314 & 55954 & - & 3 & 1 & 5 & - \\
\hline 06.сен & 161 & 43643 & 12315 & 55959 & - & 3 & 1 & 5 & - \\
\hline 07.сен & 162 & 43646 & 12317 & 55963 & - & 3 & 1 & 4 & - \\
\hline 08.сен & 163 & 43649 & 12318 & 55967 & - & 3 & 1 & 4 & - \\
\hline 09.сен & 164 & 43652 & 12319 & 55971 & - & 3 & 1 & 4 & - \\
\hline 10.сен & 165 & 43654 & 12320 & 55974 & - & 3 & 1 & 4 & - \\
\hline 11.сен & 166 & 43657 & 12321 & 55978 & - & 2 & 1 & 3 & - \\
\hline 12.сен & 167 & 43659 & 12322 & 55981 & - & 2 & 1 & 3 & - \\
\hline
\end{tabular}

П.С. Гринчук, С.П. Фисенко. Прогноз заболеваемости коронавирусом. Две волны. 20.05.2020 Страница 13 


\begin{tabular}{|c|c|c|c|c|c|c|c|c|c|}
\hline 1 & 2 & 3 & 4 & 5 & 6 & 7 & 8 & 9 & 10 \\
\hline 13. сен & 168 & 43661 & 12323 & 55984 & - & 2 & 1 & 3 & - \\
\hline 14. сен & 169 & 43663 & 12324 & 55987 & - & 2 & 1 & 3 & - \\
\hline 15. сен & 170 & 43665 & 12325 & 55990 & - & 2 & 1 & 3 & - \\
\hline 16. сен & 171 & 43667 & 12326 & 55993 & - & 2 & 1 & 3 & - \\
\hline 17. сен & 172 & 43669 & 12326 & 55995 & - & 2 & 1 & 2 & - \\
\hline 18. сен & 173 & 43670 & 12327 & 55997 & - & 2 & 1 & 2 & - \\
\hline 19. сен & 174 & 43672 & 12328 & 56000 & - & 2 & 1 & 2 & - \\
\hline 20. сен & 175 & 43673 & 12328 & 56002 & - & 1 & 1 & 2 & - \\
\hline 21. сен & 176 & 43675 & 12329 & 56004 & - & 1 & 1 & 2 & - \\
\hline 22. сен & 177 & 43676 & 12329 & 56006 & - & 1 & 1 & 2 & - \\
\hline 23. сен & 178 & 43678 & 12330 & 56007 & - & 1 & 1 & 2 & - \\
\hline 24. сен & 179 & 43679 & 12330 & 56009 & - & 1 & 0 & 2 & - \\
\hline 25. сен & 180 & 43680 & 12331 & 56011 & - & 1 & 0 & 2 & - \\
\hline 26. сен & 181 & 43681 & 12331 & 56012 & - & 1 & 0 & 2 & - \\
\hline 27. сен & 182 & 43682 & 12332 & 56014 & - & 1 & 0 & 1 & - \\
\hline 28. сен & 183 & 43683 & 12332 & 56015 & - & 1 & 0 & 1 & - \\
\hline 29. сен & 184 & 43684 & 12332 & 56016 & - & 1 & 0 & 1 & - \\
\hline 30.сен & 185 & 43685 & 12333 & 56017 & - & 1 & 0 & 1 & - \\
\hline 01. окт & 186 & 43686 & 12333 & 56019 & - & 1 & 0 & 1 & - \\
\hline 02. окт & 187 & 43686 & 12333 & 56020 & - & 1 & 0 & 1 & - \\
\hline 03. окт & 188 & 43687 & 12334 & 56021 & - & 1 & 0 & 1 & - \\
\hline 04. окт & 189 & 43688 & 12334 & 56022 & - & 1 & 0 & 1 & - \\
\hline 05. окт & 190 & 43689 & 12334 & 56023 & - & 1 & 0 & 1 & - \\
\hline 06. окт & 191 & 43689 & 12334 & 56024 & - & 1 & 0 & 1 & - \\
\hline 07. окт & 192 & 43690 & 12334 & 56024 & - & 1 & 0 & 1 & - \\
\hline 08. окт & 193 & 43691 & 12335 & 56025 & - & 1 & 0 & 1 & - \\
\hline 09. окт & 194 & 43691 & 12335 & 56026 & - & 1 & 0 & 1 & - \\
\hline 10. окт & 195 & 43692 & 12335 & 56027 & - & 1 & 0 & 1 & - \\
\hline 11. окт & 196 & 43692 & 12335 & 56027 & - & 0 & 0 & 0 & - \\
\hline
\end{tabular}

